Once altered by $\mathrm{KBr}$, conditions for restoring the original serum pattern have yet to be determined. The mobility of the majority of serum proteins was unaffected by either heparin or oleic acid. The latter did alter the mobility of some proteins other than those described above.

Department of Biochemistry,

RICHARD Holmes

Alfred I. du Pont Institute,

Wilmington, Del. Ig899 (U.S.A.)

I R. Holmes, J. Cell Biol., 32 (1967) 297.

2 R. Holmes, Biochim. Biophys. Acta, I33 (I967) I 74.

3 D. G. Cornwell and F. A. Kruger, J. Lipid Res., 2 (I96I) 1 Io.

Received October $24^{\text {th, }}$ I968

Biochim. Biophys. Acta, I 75 (1969) 209-2 I I

BBA $33 \mathbf{I} 29$

\title{
Application of specialized techniques for specific staining of peptide maps on various media
}

Combinations of specific color reactions useful in peptide mapping on Whatman filter papers have been described in a previous communication ${ }^{1}$. This paper introduces a new combination of specific reactions for staining peptide maps on Whatman No. 3MM paper ${ }^{2}$, and to a limited extent, on thin-layer plates. Cellulose plates used were E. Merck thin-layer chromatographic cellulose-precoated plates. Silica gel plates were prepared ${ }^{3}$ from Merck silica gel $\mathrm{G}$ and Koch-Light amylopectin.

Staining of peptide maps on paper. An optimal combination of several staining reactions on one peptide map is desirable, in order to eliminate variations seen in duplicates and to conserve time and materials. The new staining sequence described here combines 5 reactions on a single $3 \mathrm{MM}$ paper. Best results may be obtained on a peptide map prepared from an aliquot of digest representing at least $0 . \mathrm{I} \mu$ mole original protein.

A distinct advantage of this staining sequence is the combination of a highly sensitive test for arginine with the Pauly reaction for histidine and tyrosine; the Sakaguchi reagent for arginine and the Pauly reagent are incompatible on the same paper $^{1}$. A disadvantage is that the tyrosine reaction is weak as applied here; occasionally it does not work at all.

These reactions are performed in the order in which they are described. To avoid confusion, the spots are marked after each reaction, and the results incorporated on a composite tracing.

I. The platinic iodide reaction for reducing sulfur is performed as described previously ${ }^{1}$. The paper must be thoroughly dried after electrophoresis, since remaining traces of the solvents used, as well as pyridine or collidine in the atmosphere, seem to interfere with this reaction. 
2. The phenanthrenequinone reaction for arginine ${ }^{4}$ : The paper is then dipped through a solution consisting of equal volumes of $0.02 \%$ phenanthrenequinone in abs. ethanol and $10 \% \mathrm{NaOH}$ in $60 \%$ ethanol (freshly prepared). After 20 min, the spots show brilliant greenish or bluish white fluorescence against a dark blue background under $366-\mathrm{m} \mu$ ultraviolet light. Tryptophan peptides show a darker blue fluorescence and may be verified by previous examination of the unstained paper under $366-\mathrm{m} \mu$ ultraviolet light. At this point the paper is air-dried $2-3 \mathrm{~h}$.

3. Pauly reaction: The paper is then sprayed with cold diazotized sulfanilic acid ( 2 parts sulfanilic acid plus I part $\left.\mathrm{NaNO}_{2}\right)^{1}$. It is not necessary to spray with sodium carbonate, since the paper is already alkaline from Reaction 2. It is important to spray the paper with a fine mist, to avoid soaking, and to dry thoroughly before further staining.

4. The paper is then dipped through a modified ninhydrin reagent, adapted by YAMADA AND ITANO ${ }^{4}$ ( $\mathrm{g}$ ninhydrin, $80 \mathrm{ml}$ acetone, $20 \mathrm{ml}$ glacial acetic acid, and o. $\mathrm{I}$ cadmium acetate dissolved in $5 \mathrm{ml}$ water). The paper is dried in the air, then heated gently (not over $60^{\circ}$ ). Intense red-violet spots develop.

5 . Finally, the paper is dipped through the $\alpha$-nitroso- $\beta$-naphthol reagent for tyrosine, as described previously ${ }^{1}$. The spots are unstable and must be recorded immediately.

Staining of peptide maps on thin-layer plates. The staining techniques for peptide maps on thin-layer plates have to be modified because of the differences in the media. A $20 \mathrm{~cm} \times 20 \mathrm{~cm}$ thin-layer map can be made from an aliquot of digest representing $0.0 \mathrm{I}-0.03 \mu$ mole protein, only $0 . \mathrm{I}-0.3$ of that required for a standard-size paper.

It is necessary to use a spraying rather than dipping technique for staining the thin-layer maps. All the reagents named above do work on thin layers, except for Reaction I. A modified platinic iodide reagent ${ }^{5}$ which has been used successfully on cellulose thin layers is described below.

For reproducibility, considerable practice in spraying reagents is necessary to attain minimum variation in the amount and distribution of reagent on the plates. Because the saturation capacity of the thin layers is less than that of $3 \mathrm{MM}$ paper, not as many reagents can be applied to the plates as to paper. On some thin-layer media the spots may "run" with excessive spraying. This difficulty can be overcome by successive light spraying and drying after each application.

In the tyrosine reaction or the Ehrlich reaction, it is sometimes difficult to fade the cadmium-ninhydrin spots on thin-layer maps. Therefore, the best tyrosine or Ehrlich staining is obtained on plates which have been stained previously only with ninhydrin buffered with pyridine acetate ${ }^{1}$ or collidine ${ }^{3}$.

The following staining combinations have been used successfully on cellulose or silica gel thin layers. Combinations I and 3 work on both cellulose and silica gel, whereas combinations 2 and 4 work only on cellulose.

I. Phenanthrenequinone reaction for arginine, followed by the cadmium-ninhydrin reaction.

2. Phenanthrenequinone reaction, followed by the Pauly reaction. Cadmium-ninhydrin reacts weakly after this combination.

3. Buffered ninhydrin spray, followed by the tyrosine reaction or the Ehrlich reaction ${ }^{1}$.

4. Platinic iodide-starch reagent ${ }^{5}$. Soln. A: o.I $\mathrm{ml} \mathrm{Io} \%$ chloroplatinic acid plus 
$7.0 \mathrm{ml} \mathrm{I.I \%} \mathrm{KI} \mathrm{plus} 7.0 \mathrm{ml} \mathrm{H} \mathrm{H}_{2} \mathrm{O}$. Soln. B: $80.0 \mathrm{ml} 0.5 \%$ starch solution. Just before use, mix A and B. Spray lightly with the reagent; methionine or aminoethylcysteine peptides give an immediate blue color. Subsequent spraying gives many bleached spots on a tan background, some due to $-\mathrm{SH}$ or $-\mathrm{S}_{-} \mathrm{S}_{-}$, and some apparently nonspecific. After the plate is dry, it is sprayed with ninhydrin buffered with pyridine acetate.

This work was supported by a grant from the Netherlands Organization for the Advancement of Pure Research (Z.W.O.), by the Florida Heart Association grant $68 \mathrm{AG} 8$, and by the National Science Foundation research grant GB 7876 (U.S.A.). The authors wish to thank RUTH V. MARTin for technical assistance. One of the authors (C.W.E.) acknowledges the help and support of the University of Utrecht and Dr. R. E. BALlieuX, Division of Immunochemistry, during a period of research in his laboratory.

Department of Biochemistry, Caroline W. Easley University of Florida, College of Medicine, Gainesville, Fla. (U.S.A.)

Division of Immunochemistry,

Department of Medicine,

University Hospital, Marleen De Vijlder

Utrecht (The Netherlands)

I C. W. Easley, Biochim. Biophys. Acta, Io7 (1965) 386.

2 A. M. Katz, W. J. Dreyer and C. B. Anfinsen, J. Biol. Chem., 234 (1959) 2897.

3 R. E. Ballieux, T. Sebens and N. A. J. Mul, Protides Biol. Fluids, Pros. Colloq., I4 (I966) 527 .

4 S. Yamada and H. A. Itano, Biochim. Biophys. Acta, 139 (1966) $53^{8}$.

5 L. R. NJAA, Acta Chem. Scand., I 7 (1963) I I69.

Received September 9th, Ig68 